\title{
Renal Function Indices are Distorted by Chronic Consumption of Thermoxidised Palm Oil
}

\author{
Favour Nyoh Beshel ${ }^{1,2 *}$, Justin Atiang Beshel ${ }^{1,2}$, Victoria Oluwatosin Imade $^{2}$ \\ ${ }^{1}$ Department of Physiology, Faculty of Basic Medical Sciences, College of Medical Sciences, University of Calabar, PMB 1115, Calabar, Cross River \\ State, Nigeria \\ ${ }^{2}$ Department of Physiology, Faculty of Biomedical Sciences, Kampala International University, Western Campus, P. O. Box 71, Ishaka, Bushenyi \\ District, Uganda
}

\begin{tabular}{ll}
\hline DOI:10.36348/SJMPS.2019.v05i09.012 & | Received: 17.09.2019| Accepted: 25.09.2019| Published: 30.09 .2019 \\
*Corresponding author: Favour Nyoh Beshel &
\end{tabular}

\section{Abstract}

Fresh palm oil is known to compose of vitamin A and E; two well known antioxidants which combat alot of ailments caused by reactive oxygen species. Thermoxidized palm oil on the other hand has deleterious effects on some organs. This study was done to find out the effects of chronic consumption of palm oil on some renal function indices (protein, glucose and creatinine) in rats. Thirty male albino rats (weighing 140g-160g) of the wistar strain were randomly divided into three groups of ten rats each namely: control; (fed normal rat chow), FPO (fed 15\%w/w fresh palm oil diets) and TPO (fed $15 \% \mathrm{w} / \mathrm{w}$ thermoxidized palm oil diets). All groups had free access to tap water. Results showed that plasma protein levels in TPO-fed animals were significantly $(\mathrm{P}<0.001)$ higher compared with control and FPO-fed groups. Creatinine levels were significantly $(\mathrm{P}<0.001)$ higher in TPO-fed group than those of the control and FPO-fed groups. Urine protein, glucose and creatinine levels in the TPO-fed group were significantly $(\mathrm{P}<0.001)$ higher than those of control and FPO groups. Conclusion: Chronic consumption of thermoxidized palm oil distorts renal handling of protein, glucose and Creatinine, while fresh palm oil maintains these renal function indices.

Keywords: Fresh palm oil, thermoxidised palm oil, hyperproteinemia, proteinuria, glycosuria, reactive oxygen species, renal function indices.

Copyright @ 2019: This is an open-access article distributed under the terms of the Creative Commons Attribution license which permits unrestricted use, distribution, and reproduction in any medium for non-commercial use (NonCommercial, or CC-BY-NC) provided the original author and source are credited.

\section{INTRODUCTION}

As the most widely produced vegetable oil, palm oil is consumed as cooking oil (fresh and thermally oxidized) in most parts of Africa, especially Nigeria [1-3]. Apart from being used as an ingredient in a variety of products, it is also used in the making of margarine and shortening [4]. Food producers choose palm oil because it has a distinct quality, requires little or no hydrogenation and prolongs the shelf-life of different products [4].

In its fresh form, palm oil has many health attributes. It is the largest natural source of tocotrienol which is the most potent form of vitamin E [4], which act as antioxidants [5], strengthen the immune system, protects the skin cells from toxins and ultra violet radiation [6] stimulate rapid recovery from induced heart attack [7], and has anti-cancer properties [8]. They also have a nephroprotective action against lipidinduced chronic renal dysfunction in rats [9].
Fresh palm oil is also rich in carotenoids. As the richest natural source of carotenoids (about 15 times more than carrots and 300 times more than tomatoes) [4] it's consumption can prove very healthy for the eyes. The human body uses carotenoids as vitamin A. It can also improve on the immune system as a result of its unique ability to protet cells from free radicals [4].

Despite this wide array of advantages of consuming palm oil in its fresh state, there are still some controversies about it. For many years now, it has been established that the primary cholesterol elevating fatty acids are the saturated fatty acids with 12 (Lauric acid), 14(myristic acid) and 16 (palmitic acid) carbon atoms are associated with a concomitant increase in the risk of coronary heart disease [4]. Mensink et al., [10] conducted a study on 35 patients and showed that palmitic acid which makes up 44per cent of palm oil increased cholesterol ratio more than other saturated fatty acids including lauric and myristic acids which are abundant in kernel and coconut oil. Based on this and other studies, the World Health Organization stated that 
there is 'convincing evidence' that palmitic acid increases the risk of cardiovascular disease [11].

Oxidized palm oil poses potential dangers to the physiological and biochemical functions of the body [3]. It has also been shown to have adverse effects on the plasma lipid profile, free fatty acids, phospholipids and cerebrosides [3, 4]. Available evidence suggests that at least part of the oxidized palm oil impact on health is due to the generation of toxicants (free radicals) due to oxidation. Free radicals cause the generation of reactive oxygen species (ROS) in the system, which are very detrimental to health. Recent studies have also shown that consumption of oxidized unsaturated fatty acids may contribute to the pathogenesis of atherosclerosis by increasing lipid per oxidation and total cholesterol levels [12]. Additionally, oxidized palm oil induces reproductive toxicity and organ toxicity particularly of the kidneys $[13,4]$.

The kidneys are the major organs responsible for the excretion of waste products from the blood, and the regulation of numerous parameters such as $\mathrm{pH}$ regulation, water, electrolytes, the release of hormones, blood pressure, production of red blood cells (erythropoiesis) and producing vitamin D which keeps the bones strong and healthy. The importance of the kidneys can therefore not be underestimated. Any danger to this organ will lead to drastic irregularities in all of the above. Unfortunately, it is very susceptible to oxidative stress which results from an imbalance of reactive oxygen species (ROS) [14]. Oxidized palm oil is concentrated with free radicals that can generate reactive oxygen species [12]. The consumption rate of fresh Palm oil (which is said to constitute of $44 \%$ oleic acid [10] and thermoxidised palm oil (loaded with free radicals [12], is on the rise in Africa especially West Africa $[2,3]$.

Do the actions of the powerful antioxidants in fresh palm oil far outweigh the effects of its saturated fat component? To what extent does chronic consumption of thermoxidized palm oil affect the functionality of the kidneys? The aim of this study therefore is to compare the effects of fresh and thermoxidized palm oil on some renal function indices viz: protein, glucose and creatinine.

\section{MATERIALS AND METHODS Experimental Animals}

Thirty male albino rats of the Wistar strain weighing between 140-160 $\mathrm{g}$ at the beginning of the experiment were randomly assigned to three groups of ten rats each, respectively: Control (fed normal rat chow), FPO (fed 15\%w/w mill purchased fresh palm oil diets), and thermoxidized palm oil group (PPO; fed $15 \% \mathrm{w} / \mathrm{w}$ thermoxidized palm oil diet)

\section{Preparation of Palm Oil Diets}

Ten litres of fresh palm oil was purchased directly from the palm oil mill at Ugep in Yakurr Local Government Area, Cross River State and immediately stored in a dark container. The palm oil was hereafter divided into two equal parts of 5 litres each. One part was left fresh and still stored in the dark container to prevent any form of oxidation. The other part was thermoxidized using the method of previous workers [15]. Briefly, Fresh palm oil was heated in a stainless steel pot over a heating mantle at a temperature of $190^{\circ} \mathrm{C}$ for five consecutive times. Each round of heating lasted for 20mins, and then allowed to cool for 5 mins before the commencement of the next round of heating. It was also stored in a dark container too to prevent further oxidation. Palm oil diets were formulated as previously reported by Osim et al., [2] and Owu et al., [15]. Briefly, eighty five grams of rat chow was mixed with fifteen grams of fresh or thermoxidized palm oil which is the usual composition of a typical Black African diet. The peroxidation number of the TPO was 5.20. The peroxide value was determined using the standard AOCS method [16]. All animals were fed their separate diets for 12 weeks. Free access to water was allowed for each animal. They were each kept in separate metabolic cages throughout the duration of the experiment.

Note The diets were freshly prepared daily. The research was conducted in accordance with internationally accepted principles for care and use of animals as recommended in the declaration of Helsinki [17].

\section{Experimental Procedure}

This was done according to the method of Odigie et al., [18]. Briefly, the animals were first weighed and anaesthesized with a mixture of 1 percent (w/v) alpha chloralose and 25 per cent (w/v) urethane in normal saline at a dose of $5 \mathrm{ml} / \mathrm{kg}$ body weight intraperitoneally. It has previously been reported that this preparation does not alter resting blood pressure, heart rate and cardiovascular responses for atleast 3 hours after anaesthesia. A tracheotomy was performed to guarantee free breathing. A cut was made on the right thigh and the muscles carefully teased to expose the femoral vein, artery and sciatic nerve (lateromedially). The right femoral vein was separated and cannulated. However, care was taken to ensure that this cannulation was done within at least 5mins of separating from connective tissue because of the collapsible nature of veins). The cannula was connected to the infusion pump (11plus, Havard apparatus, Holliston MA, USA) for the infusion of sterile normal saline solution at a rate of $0.06 \mathrm{ml} / \mathrm{min}$.

Through a small lower abdominal incision, the urinary bladder was cannulated with a short retaining 
catheter (pp100, polythene tubing). The urethra was ligated to prevent voiding of urine.

\section{Collection of Blood and Urine}

After the equilibration period (a period within which three consecutive 20min urine collections yielded constant or the same volume) of 60mins, urine samples were collected in pre-weighed vials for another $60 \mathrm{~min}$ period. The urine samples were thereafter stored in a freezer until when required. Terminal blood samples were also collected from the left femoral vein into heparinized tubes and blood plasma was immediately separated by centrifugation $(3000 \mathrm{x} g$ for 10 mins). Separated plasma was put in Eppendorf tubes and stored in the freezer until when needed.

\section{Statistical Analysis}

The results were expressed as mean \pm standard error of mean (SEM). The results were analysed using graphPad prism software version 5(GraphPad Software, SanDiego, CA). One-way analysis of variance
(ANOVA) was used to compare means followed by a post hoc Turkey's multiple comparison test where $p$ values were significant $p<0.05$ was considered significant.

\section{RESULTS AND DISCUSSION RESULTS}

Comparison of the mean plasma concentrations of protein, glucose and creatinine in the control, FPO and TPO groups

The results of the comparison of mean plasma concentrations of protein, glucose and creatinine in the plasma of control, fresh palm oil-fed (FPO) and thermoxidized palm oil-diet fed (TPO) rats are shown in the table below. The mean concentration of protein, glucose and creatinine in the FPO-diet fed group were not significantly different from that of control. However, the concentration of creatinine in plasma of the TPO-diet fed group was significantly $(\mathrm{P}<0.001)$ higher than that of the control and FPO-diet fed groups.

Table-1: Comparison of the mean plasma concentrations of protein, glucose and creatinine in the control, FPO and TPO groups

\begin{tabular}{|l|l|l|l|}
\hline PARAMETER & CONTROL & FPO & TPO \\
\hline Protein $(\mathrm{mg} / \mathrm{dl})$ & $48.03 \pm 17.0$ & $52.92 \pm 17.37^{\mathrm{NS}}$ & $200.06 \pm 32.00^{* * * *, a}$ \\
\hline Glucose $(\mathrm{mg} / \mathrm{dl})$ & $92.00 \pm 14.54$ & $100.15 \pm 5.1^{\mathrm{NS}}$ & $130.00 \pm 20.00^{* * *, a}$ \\
\hline Creatinine $(\mathrm{mg} / \mathrm{dl}$ & $0.17 \pm 0.03$ & $0.14 \pm 0.02^{\mathrm{NS}}$ & $0.5 \pm 0.04^{* * * *, a}$ \\
\hline
\end{tabular}

Key:

$$
\begin{aligned}
& \text { NS = not significant vs control } \\
& * * *=\mathrm{P}<0.001 \text { vs control } \\
& \mathrm{a}=\mathrm{P}<0.001 \text { vs FPO }
\end{aligned}
$$

Comparison of the mean concentration of protein, glucose and creatinine in the urine of control, FPO and TPO groups

Table-2 (below) shows the results of the comparison of mean plasma concentrations of protein, glucose and creatinine in the urine of control, fresh palm oil-diet fed (FPO) and thermoxidized palm oil-diet fed (TPO) rats. On comparing the mean urine concentrations of the three solutes in the different groups, their differences were similar to their differences in plasma viz. The mean concentration of protein, glucose and creatinine in the FPO-diet fed group were not significantly different from that of control. However, the concentration of protein, glucose and creatinine in plasma of the TPO-diet fed group was significantly $(\mathrm{P}<0.001)$ higher than that of the control and FPO-diet fed groups.

Table-2: Comparison of the mean concentration of protein, glucose and creatinine in the urine of control, FPO and TPO groups

\begin{tabular}{|l|l|l|l|}
\hline Parameter & Control & FPO & TPO \\
\hline Protein $(\mathrm{md} / \mathrm{dl})$ & $4.00 \pm 0.5$ & $4.76 \pm 0.47^{\mathrm{NS}}$ & $12.51 \pm 1.75^{* * *, a}$ \\
\hline Glucose $(\mathrm{mg} / \mathrm{dl})$ & 0.00 & $0.00^{\mathrm{NS}}$ & $15.22 \pm 1.11^{* * * *, \mathrm{a}}$ \\
\hline Creatinine $(\mathrm{mg} / \mathrm{dl})$ & $59.82 \pm 2.31$ & $58.67 \pm 2.08^{\mathrm{NS}}$ & $97.04 \pm 0.28^{* * *, a}$ \\
\hline
\end{tabular}

Key:

$$
\begin{aligned}
& \mathrm{NS}=\text { not significant vs control } \\
& * * *=\mathrm{P}<0.001 \text { vs control } \\
& \mathrm{a}=\mathrm{P}<0.001 \text { vs FPO }
\end{aligned}
$$

\section{DISCUSSION}

The average concentration of proteins in plasma is approximately $52 \mathrm{mg} / \mathrm{dl}$. The plasma protein concentration of control and FPO-diet fed animals fell within this range $(48.03 \pm 17.01 \mathrm{mg} / \mathrm{dl}$ and $52.92 \pm 17.37$ respetively ) while that of TPO-diet fed animals went way beyond this $(200.00 \pm 32.08 \mathrm{mg} / \mathrm{dl}$ respectively). The latter was significantly higher than control and FPOdiet fed mean concentration. There could be a couple of reasons for pathologically increased plasma protein including breakdown of the immune system which could be as a result of increased release of hemoglobin from damaged red blood cells which exceeds the binding capacity of haptoglobin [19]. That this may be the case, was shown in a study by Mesembe et al., [20] that chronic consumption of thermoxidized palm oil led to destruction of red blood cells and resulted in 
hemolytic anaemia. Also, chronic consumption of thermoxidised palm oil can eventually lead to the generation of reactive oxygen species (ROS) [12]. The augmented generation of reactive oxygen species and increased oxidative stress have been implicated in the pathogenesis of renal injury, which may subsequently lead to both functional and structural renal abnormalities [21] An accumulation of ROS play an important role in the progression of inflammatory disorders [22]. This could lead to hyperproteinemia.

In the present study, the test animals consumed thermoxidized palm oil chronically. The TPO-diet fed animals also presented with proteinuria. The presence of inflammation is a well documented factor influencing the development of oxidative stress in kidney failure [23]. ROS may affect cells of the host organism especially the sites of inflammation in addition to playing a role in the defense system against other agents. This effect plays a role in a variety of renal diseases such as glomerulonephritis and tubulointerstitial nephritis which can contribute to proteinuria and other conditions $[24,25]$. The results of mean protein concentration in the plasma of control and FPO-diet fed animals were not significantly different from each other.

The plasma glucose concentrations in the control and test groups were within normal range. However, the concentration of glucose in the urine of TPO-diet fed animals was significantly higher than those of control and FPO-diet fed groups. This scenario is typical of renal glycosuria which is usually an inherited disorder where simple sugar is excreted in urine despite normal blood glucose levels... a rare disorder due mainly to mutations in the sodium-glucose cotransporter 2 gene (SGLT2) [26]. Previous studies have shown that chronic consumption of thermoxidized palm oil led to an increase in sodium excretion [27]. Also, oxidized palm oil consumption increases free radicals which increase the concentration of ROS [12] which is known to lead to inflammation [22] and destruction of tissues [28]. In this study, the tubules may have undergone some sort of inflammation which may have destroyed the transport proteins (SGLT2) responsible for the transport of glucose, hence the presence of glucose in the urine in spite of normal blood glucose levels.

Creatinine is a waste product made by the body during regular metabolism [29]. Plasma creatinine levels are usually measured to determine acute or chronic renal insufficiency [30, 31, 29]. The creatinine concentration of the control and FPO-fed animals were within normal range. However, the level in the TPOdiet fed group was significantly higher than the control and FPO-diet fed groups. It must be noted that the plasma creatinine levels in rats are variable and therefore unreliable for measurement of GFR unlike the case in humans. Therefore, even though the test values may seem normal compared to human values, and creatinine levels which could be affected by physiological factors such as age, body weight and exercise [31] are considered abnormal (high) in this study because all the animals were exposed to the same experimental conditions.

High plasma creatinine levels indicate renal dysfunction: chronic kidney disease or generalised renal dysfunction [29, 32]. In this study, this was probably the case because similar increases in the levels of other solutes such as glucose and protein were noted. Apart from that, the animals were on a diet of thermoxidized palm oil which is known to generate free radicals which increase the levels of reactive oxygen species (ROS) in the body [12]. When these species flood the body such that they overwhelm the scavenging enzymes responsible for mopping them up, oxidative stress results [23]. The kidneys are very susceptible to oxidative stress [14]. Renal sources for ROS are activated macrophages, vascular cells, and various glomerular cells. ROS are also thought to contribute to ischemia reperfusion injury in the kidney [33]. From the foregoing, it is possible that the TPO-diet fed animal's kidneys functions may have been compromisedd owing to the chronic consumption of this ROS-generating substance (thermoxidized palm oil.

As far as the FPO-diet fed animals were concerned, the mean concentration in blood and urine of all these renal function indices ( protein, glucose and creatinine) were very similar to that of control animals. This shows that the actions of the antioxidants in fresh palm oil far outweigh the actions of the saturated palmitic acid. This is supported by Several investigators who reported that tocotrienols T3 have strong antioxidant activity and protects efficiently against some free radical-related diseases [34, 9].

\section{CONCLUSION}

Chronic consumption of thermoxidized palm oil distorts some renal function indices (serum and urine protein, glucose and creatinine) while chronic consumption of fresh palm oil does not alter but maintains them.

\section{REFERENCES}

1. Cotrell, R. C. (1991). Nutritional aspects of palm oil. American Journal of Clinical Nutrition. 53:989-1009.

2. Osim, E. E., Owu, D. U., Isong, E. U., \& Umoh, I. B. (1994). Influence of chronic consumption of thermoxidized fresh palm oil diets on basal metabolic rate, body weight and morphology of tissue in rats. Discovery and innovation, 6(4), 389396.

3. Ebong, P. E., Owu, D. U., \& Isong, E. U. (1999). Influence of palm oil (Elaesis guineensis) on 
health. Plant Foods for Human Nutrition, 53(3), 209-222.

4. Mukherjee, S., \& Mitra, A. (2009). Health effects of palm oil. Journal of human Ecology, 26(3), 197-203.

5. Fife, B. (2005). Red palm oil: A daily dose of vitamins from a cooking oil. J. Biol. Chem, 287, 43508-43515.

6. Stone, B. (2009). Is palm oil good for you? Alternative \&natural diet \&nutrition fitness \& exercise Health Care Technology. Part 3 of 3. In the series: The controversy over tropical oils.

7. Esterhuyse, A. J., Du Toit, E. F., \& Van Rooyen, J. (2005). Dietary red palm oil supplementation protects against the consequences of global ischemia in the isolated perfused rat heart. Asia Pacific journal of clinical nutrition, 14(4), 340347.

8. Yano, Y., Satoh, H., Fukumoto, K., Kumadaki, I., Ichikawa, T., Yamada, K., ... \& Yano, T. (2005). Induction of cytotoxicity in human lung adenocarcinoma cells by 6-O-carboxypropyl- $\alpha-$ tocotrienol, a redox-silent derivative of $\alpha$ tocotrienol. International journal of cancer, 115(5), 839-846.

9. Rashid Khan, M., Ahsan, H., Siddiqui, S., \& Siddiqui, W. A. (2015). Tocotrienols have a nephroprotective action against lipid-induced chronic renal dysfunction in rats. Renal failure, 37(1), 136-143.

10. Mensink, R. P., Zock, P. L., Kester, A. D., \& Katan, M. B. (2003). Effects of dietary fatty acids and carbohydrates on the ratio of serum total to HDL cholesterol and on serum lipids and apolipoproteins: a meta-analysis of 60 controlled trials. The American journal of clinical nutrition, 77(5), 1146-1155.

11. WHO. (2003). Diet, nutrition and the prevention of Chronic Diseases. WHO Technical Report Series 916. Geneva: WHO, P82, 88 \& 88c.

12. Adam, S. K., Soelaiman, I. N., Umar, N. A., Mokhtar, N., Mohamed, N., \& Jaarin, K. (2008). Effects of repeatedly heated palm oil on serum lipid profile, lipid peroxidation and homocysteine levels in a post-menopausal rat model. McGill Journal of Medicine: MJM, 11(2), 145-151.

13. Osim, E. E., Owu, D. U., \& Etta, K. M. (1995). Mean arterial pressure and lipid profile in rats following chronic ingestion of palm oil diets. African Journal of medicine and Medical Sciences.

14. McCullough, P. A. (2004). Cardiovascular disease in chronic kidney disease from a cardiologist's perspective. Current opinion in nephrology and hypertension, 13(6), 591-600.

15. Owu, D. U., Orie, N. N., \& Osim, E. E. (1997). Altered responses of isolated aortic smooth muscle following chronic ingestion of palm oil diets in rats. African journal of medicine and medical sciences, 26, 83-86.

16. AOCS. (1989). Official Methods and Reccomended Practices of the American oil. Chemists Society. 5th edition champaign I. L, 4862.

17. Helsinki. (1964). World Medical Association Declaration of Helsinki. Adopted by the 18th WMA General Assembly, Helsinki, Finland.

18. Odigie, I. P., Ladipo, C. O., Ettarh, R. R., \& Izegbu, M. C. (2004). Effect of chronic exposure to low levels of lead on renal function and renal ultrastructure in SD rats. Nigerian Journal of Physiological Sciences, 19(1), 27-32.

19. Grauer, G. F. (2007). How is proteinuria detected? Epidemiological project International Renal Interest Society. Novartis animal health Inc.

20. Mesembe, O. E., Ibanga, I., \& Osim, E. E. (2004). The effects of fresh and thermoxidized palm oil diets on some haematological indices in the rat. Nigerian Journal of Physiological Sciences, 19(1), 86-91.

21. Chade, A. R., Rodriguez-Porcel, M., Grande, J. P., Zhu, X., Sica, V., Napoli, C., ... \& Lerman, L. O. (2003). Mechanisms of renal structural alterations in combined hypercholesterolemia and renal artery stenosis. Arteriosclerosis, thrombosis, and vascular biology, 23(7), 1295-1301.

22. Mittal, M., Siddiqui, M. R., Tran, K., Reddy, S. P., \& Malik, A. B. (2014). Reactive oxygen species in inflammation and tissue injury. Antioxidants \& redox signaling, 20(7), 1126-1167.

23. Samouilidou, E. C., Grapsa, E. J., Kakavas, I., Lagouranis, A., \& Agrogiannis, B. (2003). Oxidative stress markers and C-reactive protein in end-stage renal failure patients on dialysis. International urology and nephrology, 35(3), 393-397.

24. Ichikawa, I., Kiyama, S., \& Yoshioka, T. (1994). Renal antioxidant enzymes: their regulation and function. Kidney international, 45(1), 1-9.

25. Klahr, S. (1997). Oxygen radicals and renal diseases. Mineral and electrolyte metabolism, 23(3-6), 140-143.

26. Calado, J., Soto, K., Clemente, C., Coreia, B., \& Rueff, J. (2004). Novel compound heterozygous mutations in SGLTA2 are responsible for autosomal recessive renal glucosuria. Human Genetics, 114(3):314-6.

27. Beshel, F. N., Beshel, J. A., Osim, E. E., \& Antai, A. B. (2018). Derrangement of $\mathrm{K}+, \mathrm{Na}+, \mathrm{Cl}-$ and HCO3- levels by Chronic Consumption of oxidized Palm Oil. Saudi Journal of Medical and Pharmaceutical Sciences, 4(10) 214-1220.

28. Osim, E. E., Owu, D. U., \& Etta, K. M. (1996). Arterial pressure and lipid profile in rats following chronic ingestion of palm oil diets. African Journal of Medicine and Medical Sciences, 25, 335-340. 
29. Gayle, C. P. (2002). Serum creatinine levelCreatinine. Medicine Online; All rights reserved.

30. Tippins, R. B., Torres, W. E., Baumgartner, B. R., \& Baumgarten, D. A. (2000). Are screening serum creatinine levels necessary prior to outpatient CT examinations?. Radiology, 216(2), 481-484.

31. Lefebvre, H. P., \& Watson, D. (2001). Plasma creatinine in dogs: try to avoid major misinterpretations. IRIS international renal interest society. 17:1232-1240.
32. Nabili, S., \& Shiel, W. C. (2009). Creatinine blood test. Medicine Net.com.

33. Dobashi, K., Ghosh, B., Orak, J. K., Singh, I., \& Singh, A. K. (2000). Kidney ischemia-reperfusion: modulation of antioxidant defenses. Molecular and cellular biochemistry, 205(1-2), 1-11.

34. Sen, C. K., Khanna, S., \& Roy, S. (2006). Tocotrienols: Vitamin E beyond tocopherols. Life sciences, 78(18), 2088-2098. 